\title{
Perspectives of interns and residents toward do-not-resuscitate policies in Saudi Arabia
}

This article was published in the following Dove Press journal:

Advances in Medical Education and Practice

14 March 2016

Number of times this article has been viewed

\author{
Abdullah S Amoudi' \\ Mohammed H Albar ${ }^{2}$ \\ Amjed M Bokhari ${ }^{3}$ \\ Sultan $\mathrm{H}_{\text {Yahya }}{ }^{4}$ \\ Anas A Merdad' \\ 'Department of Internal Medicine, \\ ${ }^{2}$ Department of Obstetrics and \\ Gynecology, ${ }^{3}$ Department of Surgery, \\ King Abdulaziz University Hospital, \\ Jeddah, ${ }^{4}$ Department of Radiology, \\ King Saud University Hospital, Riyadh, \\ Kingdom of Saudi Arabia
}

Objective: Do-not-resuscitate (DNR) orders in Saudi Arabia were first regulated by a fatwa on a national level in 1988, one that excludes the patient and their families from decision making. Although the core of this policy is taken up by all hospitals in Saudi Arabia, there is no homogeneity in implementation. Here, we appraise what interns and residents know of these policies and their attitudes toward DNR.

Methods: Interns and residents in four major hospitals in Jeddah, King Abdulaziz University Hospital, National Guard Hospital, King Fahad General Hospital, and King Fahad Armed Forces Hospital, were given a questionnaire in English with four blocks of questions.

Results: A total of 140 questionnaires were included in our study. From these questionnaires, we conclude a lack of familiarity with DNR's policies and the fatwa and also a lack of understanding when it comes to treating DNR-labeled patients. The majority opinion was to include the patient in the decision-making process who is excluded according to the fatwa. Participants considered patients' dignity, religious concerns, and legal concerns to be important in considering resuscitation.

Conclusion: We conclude a need to emphasize the issue of DNR and treatment of DNR patients in medical ethics classes in Saudi Arabia and put more effort to enact national DNR laws that include the patient in the decision-making process.

Keywords: passive euthanasia, Middle East, cross-sectional study

\section{Introduction}

In the midst of hardships and dilemmas in patient management and end-of-life care, it is important that the physician understands the patient's values and medical treatment goals, restoring health, extending life, and relieving pain and suffering. End-of-life care is defined by the National Institutes of Health in 2004, as the care provided to a person during the final stages of life. End-of-life care is also called palliative care, hospice care, and comfort care. ${ }^{1}$ End-of-life care varies throughout the world and is greatly influenced by legal, social, cultural, and religious factors. ${ }^{2,3}$

A do-not-resuscitate (DNR) order is a legally binding order to withhold cardiopulmonary resuscitation. As an extremely sensitive and controversial issue, yet a circumstance every physician is bound to face, DNR remains an ethically elusive topic. This is better demonstrated by the diversity in DNR policies enacted by different jurisdictions. ${ }^{4}$ Unlike other tasks in medicine, DNR policies and guidelines cannot be adopted from other countries, especially in Saudi Arabia, where jurisprudence remains distinct from elsewhere in the world with a strictly Islamic legal system. The literature on DNR is scanty for the Middle East. ${ }^{2}$ From here, we find it worthwhile to elaborate on the subject and carry out this cross-sectional study.
Correspondence: Abdullah S Amoudi Department of Internal Medicine, King Abdulaziz University Hospital, 21563, Hamad Jaser Street, PO Box 52234 Jeddah, Rawdah-6 District, Kingdom of Saudi Arabia

Tel +966564685093

Email Abdullah.S.Amoudi@gmail.com
Advances in Medical Education and Practice 2016:7 165-170

165

Dovepress

http://dx.doi.org/10.2147/AMEP.S9944/ (c) (1) (5) 2016 Amoudi et al. This work is published and licensed by Dove Medical Press Limited. The full terms of this license are available at https://www.dovepress.com/terms.
php and incorporate the Creative Commons Attribution - Non Commercial (unported, v3.0) License (http:///creativecommons.org/licenses/by-nc/3.0/). By accessing the work you hereby accept the Terms. Non-commercial uses of the work are permitted without any further permission from Dove Medical Press Limited, provided the work is properly attributed. For

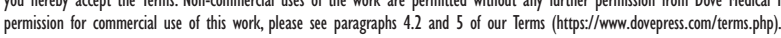


In Saudi Arabia, fatwas (religious declarations) are accepted as a source of laws on such issues. It was only as recently as 1988 that a fatwa was issued by the General Presidency of Scholarly Research and Ifta in Riyadh: Fatwa 12086. This fatwa has formed the basis for the DNR policy in the kingdom ever since. It stipulates that judging resuscitative efforts to be of no avail and issuing a DNR order is done by three "specialized and trustworthy" physicians and that the patient's family or legal guardian is not to be consulted when it comes to issuing the order. The same fatwa delineates six situations where a DNR is granted: if the patient arrives dead at the hospital, if the panel of physicians determines that the condition is untreatable and death is imminent, if the patient's condition does not make him or her fit for resuscitation, if the patient is suffering from advanced heart or lung disease or repeated cardiac arrest, if the patient is in a vegetative state, and if resuscitation is considered futile. ${ }^{5}$ According to the local guidelines, issuing a DNR order means that a DNR patient receives all treatments except for cardiopulmonary resuscitation. All interventions that ensure patient's comfort and dignity will be taken. ${ }^{3}$

Although the core of this policy is taken up by all hospitals in Saudi Arabia, ie, three consultants signing a DNR order, the data reveal a considerable degree of heterogeneity in implementing the law with regard to respecting patient autonomy, involving the patient and his family in the decision-making process, and patient characteristics that could influence the physician in signing a DNR order., ${ }^{2,6}$

Our aim in this study is to appraise the knowledge and attitudes of interns and residents toward DNR and its implication on patient care.

\section{Materials and methods}

This is a cross-sectional study conducted between May and December 2013. A questionnaire was designed in English that met the objectives and aim of the study. The questionnaire was reviewed, and the questions were made sure to be straightforward and unambiguous. This study was reviewed and approved by the ethical committee of King Abdulaziz University Hospital. Given the design of the study and the target population, only a verbal consent to be a subject in the study was asked for. Those agreeing were given the questionnaire. The questionnaire was handed to residents and interns in four hospitals in Jeddah (a convenience sample): King Abdulaziz University Hospital, National Guard Hospital, King Fahad General Hospital, and King Fahad Armed Forces Hospital. Interns in these hospitals were MBBS graduates (bachelor of medicine and surgery) going through their 1-year obligatory internships (the seventh year), while residents were those enrolled in the local residency programs to specialize. The questionnaire was distributed by hand to these doctors in their hospitals and then collected by hand for data entry. Since these two groups (interns and residents) are somewhat distinct in exposure, training, and experience, the response to the questionnaire was reported separately for them.

After identifier questions of the subjects, the questionnaire had questions that assessed the familiarity of the subjects with DNR and familiarity with the term DNR, and whether or not a clear DNR policy was implemented in their hospital and whether or not a fatwa existed that addressed DNR.

Then, a set of six questions appraised what the subjects believe are important factors in making DNR decisions: patient's dignity, religious concerns, legal concerns, risk of vegetative state, limited intensive care unit (ICU) space, and efficient use of medical resources and cost reduction.

The next questions assessed the attitude toward decision making in DNR, ie, whether to include the patient in the decision or not, whether to inform the patient of their DNR status, and whether they have the right to reject their DNR status.

The next five questions assessed issues in the treatment of DNR patients: to be generous with analgesia, to be conservative in hospital resources with DNR patients, to prioritize non-DNR patients with rounds time, and to discuss organ donation.

Statistical analysis was done with SPSS Version 20.

\section{Results}

Of the 200 questionnaires sent, 174 returned (response rate $87 \%$ ). Of the 174 returned, 140 were complete and not excluded ( 87 belonged to interns and 53 residents; $100 \%$ of them were Muslim).

While more than half of both interns and residents were familiar with the term DNR, the greatest proportion of both were not sure whether a clear DNR policy exists in their hospitals and whether a DNR policy exists at a national level (Tables 1 and 2). However, a majority of both groups agreed that a unified DNR policy is needed at a national level (Table 3).

For the next bloc of questions, while both groups considered patients' dignity, religious concerns, and legal concerns to be important in decision making in DNR, more

Table I Summary of answers to question one

\begin{tabular}{llll}
\hline \multicolumn{4}{l}{ Are you familiar with the term DNR? } \\
\hline & Yes, $\mathbf{n}(\%)$ & No, $\mathbf{n}(\%)$ & Total \\
\hline Interns & $6 I(70 \%)$ & $26(30 \%)$ & 87 \\
Residents & $49(92 \%)$ & $4(8 \%)$ & 53 \\
\hline
\end{tabular}

Abbreviation: DNR, do-not-resuscitate. 
Table 2 Summary of answers to questions two and three

\begin{tabular}{|c|c|c|c|c|}
\hline & Yes, n (\%) & No, n (\%) & I am not sure, n (\%) & Total \\
\hline \multicolumn{5}{|c|}{ Is a clear policy regarding DNR implemented in your hospital? } \\
\hline Interns & $15(17 \%)$ & $17(19 \%)$ & $55(64 \%)$ & 87 \\
\hline Residents & $17(32 \%)$ & $7(13 \%)$ & $29(55 \%)$ & 53 \\
\hline \multicolumn{5}{|c|}{ Does a fatwa exist that regulates DNR on a national level? } \\
\hline Interns & $21(24 \%)$ & $7(8 \%)$ & $59(68 \%)$ & 87 \\
\hline Residents & $15(28 \%)$ & $4(7 \%)$ & $34(65 \%)$ & 53 \\
\hline
\end{tabular}

Abbreviation: DNR, do-not-resuscitate.

were neutral in including the risk of vegetative state, limited ICU space, and efficient use of medical resources and cost reduction (Table 4).

When asked about including the patient in the decision making of their DNR status, the majority of both groups appraised believed that the patient should be involved. They also believed that they should be aware of their DNR status (Table 5).

When it comes to the in-hospital treatment of DNRlabeled patients, the majority of both groups were neutral or had no strong position toward the withdrawal of life-sustaining treatments. However, the majority of both groups agreed with or was neutral toward being generous with analgesia in DNR patients despite the risk of addiction (Table 6). The majority of both groups also agreed with being conservative in investigation and treatment of DNR-labeled patients and agreed with dedicating less time for the rounds on these patients (Table 7). Also, the great majority of both groups agreed with encouraging the discussion of organ donation with DNR-labeled patients and their families (Table 8).

\section{Discussion}

Our study highlighted a lack of knowledge in our sample of local DNR policies and of major ethical rules in the treatment of DNR-labeled patients.

In our study, we note a lack of familiarity with DNR policies in local hospitals and the national law that should regulate it (Tables 1-3). Although residents seem more familiar with DNR, a fact easily attributed to experience, both interns and residents failed to affirm whether a clear local or national policy exists. Although comparable data for different jurisdictions are lacking, this lack of familiarity can be attributed to the issue of DNR not receiving focus in local medical schools and residency programs.

Table 3 Summary of answers to question four

\begin{tabular}{|c|c|c|c|c|c|c|}
\hline \multicolumn{7}{|c|}{ A unified national DNR policy is needed? } \\
\hline & Strongly agree, n (\%) & Agree, n (\%) & Neutral, n (\%) & Disagree, n (\%) & Strongly disagree, n (\%) & Total \\
\hline Interns & $37(42 \%)$ & $35(40 \%)$ & $12(13 \%)$ & $2(2 \%)$ & I (I\%) & 87 \\
\hline Residents & $35(66 \%)$ & $3(3 \%)$ & $12(22 \%)$ & $0(0 \%)$ & $3(5 \%)$ & 53 \\
\hline
\end{tabular}

Abbreviation: DNR, do-not-resuscitate.

Table 4 Summary of answers to questions regarding which factors to be considered when making the DNR decision

\begin{tabular}{|c|c|c|c|c|c|c|}
\hline & Very important, n (\%) & Important, n (\%) & Neutral, n (\%) & Slightly important, n (\%) & Not important, n (\%) & Total \\
\hline \multicolumn{7}{|c|}{ Patients' dignity } \\
\hline Interns & $48(55 \%)$ & 17 (19\%) & $15(17 \%)$ & $3(3 \%)$ & $4(4 \%)$ & 87 \\
\hline Residents & $30(56 \%)$ & II (20\%) & $8(15 \%)$ & $4(7 \%)$ & $0(0 \%)$ & 53 \\
\hline \multicolumn{7}{|c|}{ Religious concerns } \\
\hline Interns & $44(50 \%)$ & $26(49 \%)$ & $5(5 \%)$ & $5(5 \%)$ & $7(8 \%)$ & 87 \\
\hline Resident & $33(62 \%)$ & $8(15 \%)$ & $3(5 \%)$ & I (2\%) & $8(15 \%)$ & 53 \\
\hline \multicolumn{7}{|c|}{ Legal concerns } \\
\hline Interns & $26(29 \%)$ & 36 (4I\%) & 17 (19\%) & $4(4.5 \%)$ & $4(4.5 \%)$ & 87 \\
\hline Residents & $31(58 \%)$ & $17(32 \%)$ & $4(7.5 \%)$ & $\mathrm{I}(\mathrm{I} .8 \%)$ & $0(0 \%)$ & 53 \\
\hline \multicolumn{7}{|c|}{ Risk of vegetative state } \\
\hline Interns & $20(22 \%)$ & $21(24 \%)$ & $4 I(47 \%)$ & I (I.I\%) & $4(4.5 \%)$ & 87 \\
\hline Residents & $16(30 \%)$ & $18(34 \%)$ & $15(28 \%)$ & $0(0 \%)$ & $4(7.5 \%)$ & 53 \\
\hline \multicolumn{7}{|c|}{ Limited ICU space } \\
\hline Interns & $22(25 \%)$ & $18(20 \%)$ & $24(27 \%)$ & $12(13 \%)$ & II (I2.6\%) & 87 \\
\hline Residents & $27(50 \%)$ & $7(13 \%)$ & $8(15 \%)$ & $7(13 \%)$ & $4(4.5 \%)$ & 53 \\
\hline \multicolumn{7}{|c|}{ Efficient use of medical resources and cost reduction } \\
\hline Interns & $20(23 \%)$ & $22(25 \%)$ & $25(28 \%)$ & II (I2\%) & $9(10 \%)$ & 87 \\
\hline Residents & 16 (30\%) & 12 (22\%) & II (20\%) & 3 (5.6\%) & II (20\%) & 53 \\
\hline
\end{tabular}

Abbreviations: DNR, do-not-resuscitate; ICU, intensive care unit. 
Table 5 Summary of answers to questions regarding the inclusion of patients in DNR decisions

\begin{tabular}{|c|c|c|c|c|c|c|}
\hline & Strongly agree, $\mathrm{n}(\%)$ & Agree, n (\%) & Neutral, n (\%) & Disagree, $\mathbf{n}(\%)$ & Strongly disagree, $\mathbf{n}(\%)$ & Total \\
\hline \multicolumn{7}{|c|}{ I believe that patients should be involved in decisions regarding their DNR status } \\
\hline Interns & $31(35 \%)$ & $39(44 \%)$ & $12(13 \%)$ & $5(5.7 \%)$ & $0(0 \%)$ & 87 \\
\hline Residents & $22(41 \%)$ & $20(37 \%)$ & $\mathrm{I}(\mathrm{I} .8 \%)$ & $7(13 \%)$ & $3(5.6 \%)$ & 53 \\
\hline \multicolumn{7}{|c|}{ I believe policies should include the patient as a decision maker } \\
\hline Interns & $18(20 \%)$ & $41(47 \%)$ & $20(23 \%)$ & $7(8 \%)$ & I (I.I\%) & 87 \\
\hline Residents & $19(35 \%)$ & II (20\%) & $16(30 \%)$ & $7(13 \%)$ & $0(0 \%)$ & 53 \\
\hline \multicolumn{7}{|c|}{ I believe patients have the right to reject or request (advanced directive) their DNR status } \\
\hline Interns & $35(40 \%)$ & $35(40 \%)$ & $9(10 \%)$ & $8(9 \%)$ & $0(0 \%)$ & 87 \\
\hline Residents & II (20\%) & $22(41 \%)$ & $12(22 \%)$ & $7(13 \%)$ & $\mathrm{I}(\mathrm{I} .8 \%)$ & 53 \\
\hline \multicolumn{7}{|c|}{ It is best that patients are not made aware of their DNR status } \\
\hline Interns & $4(4.5 \%)$ & II (I2\%) & $18(20 \%)$ & $35(40 \%)$ & $19(21 \%)$ & 87 \\
\hline Residents & $4(7.5 \%)$ & $3(5.6 \%)$ & $9(16 \%)$ & 50 (93\%) & 7 (I3\%) & 53 \\
\hline
\end{tabular}

Abbreviation: DNR, do-not-resuscitate.

When it comes to factors considered in DNR, both interns and residents place more importance on patients' dignity, religious concerns, and legal concerns and less on the risk of vegetative state. Both groups regarded the ICU space and cost reduction to be less important than the previous factors. This pattern in assigning importance is similar to another study conducted in the central region of Saudi Arabia in 1999. This study excluded interns from its sample and showed similar responses as to which factors are important in DNR decisions. ${ }^{6}$ These similar responses accentuate the role of culture and religion in DNR, a role so significant that it caused responses of interns, residents, and more senior physicians to become similar.

As for including the patient in the DNR decision, both residents and interns vehemently believed that patients should have a say in their DNR status (Table 5). This shows an increasing importance of patient's autonomy to physicians, even though it goes against an integral part in the fatwa issued in 1988, the part that holds physicians as the sole decision makers with the patients' and their families' wishes not considered. These results are similar to another study conducted on interns and residents in Iran and another one conducted on oncology and palliative care doctors and nurses in Singapore, where the majority believed that patients' preferences are essential in the DNR order. ${ }^{4,7}$ However, another study conducted in Japan showed that $11 \%$ of physicians believe that patients' consent is indispensable in DNR decisions. ${ }^{8}$
As for the treatment of DNR patients, the majority of both interns and residents agreed with or were neutral toward being generous with analgesia (Table 6). This does not stray far off the international and local guidelines that state that all measures should be applied to ease pain and relieve symptoms. ${ }^{2}$ As for being overly generous, the National Consensus Project for Quality Palliative Care guidelines suggest addressing concerns of narcotics and analgesics hastening death. ${ }^{9}$

As for the questions regarding withholding life-sustaining treatments, being conservative with investigations and management, and the dedication of less round time to DNRlabeled patients, the majority of both interns and residents were either neutral or agreed with the statement (Table 7). This suggests an understanding of DNR that goes against a core principle in the treatment of DNR patients, as stated so in the National Consensus Project guidelines ${ }^{9}$ and local guidelines; ${ }^{2}$ the statement that no treatment should be withheld from DNR patients and anything short of aggressive resuscitative efforts should be given. ${ }^{2}$

As for organ donation in DNR patients, an absolute majority of both interns and residents believed it should be encouraged (Table 8). Calls for integrating organ donation with routine and end-of-life care are touted in the medical community. However, no efforts explicitly acknowledge the potential for integrating organ donation, specifically with end-of-life care. ${ }^{10}$ The more integrated and disciplined the concept of end-of-life care is, the more successful measures

Table 6 Summary of answers to the question regarding analgesia

\begin{tabular}{|c|c|c|c|c|c|c|}
\hline & Strongly agree, n (\%) & Agree, n (\%) & Neutral, n (\%) & Disagree, n (\%) & Strongly disagree, n (\%) & Tota \\
\hline \multicolumn{7}{|c|}{ It is acceptable to be generous with analgesia in DNR patients, despite the risk of addiction } \\
\hline Interns & $16(18 \%)$ & $26(30 \%)$ & $30(34 \%)$ & $13(15 \%)$ & $2(2.2 \%)$ & 87 \\
\hline Residents & $9(17 \%)$ & $14(26 \%)$ & $23(43 \%)$ & 7 (I3\%) & $0(0 \%)$ & 53 \\
\hline
\end{tabular}

Abbreviation: DNR, do-not-resuscitate. 
Table 7 Summary of answers to questions regarding the treatment of DNR patients

\begin{tabular}{|c|c|c|c|c|c|c|}
\hline & Strongly agree, $\mathbf{n}(\%)$ & Agree, n (\%) & Neutral, n (\%) & Disagree, $\mathrm{n}(\%)$ & Strongly disagree, $\mathbf{n}(\%)$ & Total \\
\hline \multicolumn{7}{|c|}{ It is acceptable to withdraw life-sustaining treatment from a DNR-labeled patient } \\
\hline Interns & $\mathrm{I}(\mathrm{I} . \mathrm{I} \%)$ & $24(27 \%)$ & $35(40 \%)$ & $19(21 \%)$ & $8(9.1 \%)$ & 87 \\
\hline Residents & $0(0 \%)$ & $19(36 \%)$ & $18(34 \%)$ & $4(7.5 \%)$ & $12(22 \%)$ & 53 \\
\hline \multicolumn{7}{|c|}{ Being conservative with the investigations and treatment of DNR patients is essential to preserve hospital resources } \\
\hline Interns & $16(18 \%)$ & $32(36 \%)$ & $30(34 \%)$ & $3(3.4 \%)$ & $6(7 \%)$ & 87 \\
\hline Residents & $9(17 \%)$ & II (20\%) & $18(34 \%)$ & II (20\%) & $4(7.5 \%)$ & 53 \\
\hline \multicolumn{7}{|c|}{ Dedicating a smaller portion of my rounds for DNR patients is preferable to better manage patients with better prognosis } \\
\hline Interns & $15(17 \%)$ & $33(38 \%)$ & $18(20 \%)$ & $15(17 \%)$ & $6(7 \%)$ & 87 \\
\hline Residents & $10(19 \%)$ & $14(26 \%)$ & $18(34 \%)$ & $3(5.6 \%)$ & $8(15 \%)$ & 53 \\
\hline
\end{tabular}

Abbreviation: DNR, do-not-resuscitate.

Table 8 Summary of answers to the question regarding organ donation

\begin{tabular}{|c|c|c|c|c|c|c|}
\hline & Strongly agree, n (\%) & Agree, n (\%) & Neutral, n (\%) & Disagree, $\mathbf{n}(\%)$ & Strongly disagree, $\mathrm{n}(\%)$ & Total \\
\hline \multicolumn{7}{|c|}{ The discussion of organ donation with DNR patients/family should be encouraged } \\
\hline Interns & $37(42 \%)$ & $31(35 \%)$ & $13(15 \%)$ & $5(5.7 \%)$ & I (I.I\%) & 87 \\
\hline Residents & II (20\%) & 23 (43\%) & $8(15 \%)$ & 7 (I3\%) & 4 (7.5\%) & 53 \\
\hline
\end{tabular}

Abbreviation: DNR, do-not-resuscitate.

of organ donation become. In organ donation, the patient's wishes are respected, and if no wishes were expressed or could be expressed by the DNR-labeled patient, the issue should be discussed with the family. ${ }^{10}$ In our study, we conclude that interns and residents lacked a familiarity with DNR policy in Saudi Arabia. They also failed to distinguish that DNR patients have to be approached like other nonDNR patients when it comes to diagnosis and management, except for resuscitative efforts. Medical ethics is a part of the curriculum of every medical school, but we believe that it failed to emphasize these issues regarding DNR; we recommend that the former points be highlighted more in these courses.

As for deciding on DNR orders, interns and residents believed that the patient in question should be part of the decision-making process, a stance that coincides with ethical norms in North America and Europe and also in many hospitals in Saudi Arabia. We recommend that further efforts be taken up to homogenize this humane stance at a national level and that discussion of the issue be taken up by the Saudi legislative body (Shura Council) in order to enact national DNR laws that include the patient in the decision.

As for which factors are important in deciding on resuscitation and the issue of encouraging organ donation, interns and residents' stance goes in tandem with recommendations published within the commonly cited guidelines in North America. ${ }^{9}$ Certain limitations are noted in our study. Our sample was a convenience sample that included four major hospitals in the Western Region of Saudi Arabia. The major hospitals that we included in our study recruit many doctors that carry a North-American board, and these carry out the teaching of interns and residents in these hospitals. This might bias our results to be more similar to the North-American school of ethics. Appraising the attitudes and opinions of doctors in hospitals, where locally trained doctors make up the majority, could deviate from these results, another probable sampling bias is our inclusion of hospitals only in the western region.

Another bias is noted in two areas when it comes to the questions themselves. The first one is the language. We assumed in designing the questionnaire a strong command of English in the doctors appraised, which is false. Some residents and interns came from medical schools abroad where the curriculum was not in English. This could lead to misinterpretation of the questions, leading to invalid responses. The other area of bias is the phrasing of the questions, which we believe could have been simpler and easier to understand.

\section{Disclosure}

The authors report no conflicts of interest in this work.

\section{References}

1. Luce JM. End-of-life decision making in the intensive care unit. Am J Respir Crit Care Med. 2010;182:6-11.

2. Gouda A, Al-Jabbary A, Fong L. Compliance with DNR policy in a tertiary care center in Saudi Arabia. Intensive Care Med. 2010;36:2149-2153.

3. Takrouri MSM, Halwani TM. An Islamic medical and legal prospective of do not resuscitate order in critical care medicine. Internet $J$ Health. 2008;7:1. 
4. Ghajarzadeh M, Habibi R, Amini N, Norouzi-Javidan A, Emami-Razavi SH. Perspectives of Iranian medical students about do-not-resuscitate orders. Maedica (Buchar). 2013;8:261-264.

5. Alifta.net [webpage on the Internet]. Kingdom of Saudi Arabia: The General Presidency of Scholarly Research and Ifta. Fatwas on Medical Issues and the Sick [Fatwa no. 12086]:322-324. Available from: http:// www.alifta.net/Fatawa/FatawaChapters.aspx?languagename=en $\&$ View $=$ Page $\&$ PageID $=299 \&$ PageNo $=1 \&$ BookID $=17$. Accessed February 14, 2016.

6. Al-Mobeireek AF. Physicians' attitudes towards 'do-not-resuscitate' orders for the elderly: a survey in Saudi Arabia. Arch Gerontol Geriatr. 2000;30:151-160.
7. Yang GM, Kwee AK, Krishna L. Should patients and family be involved in "Do not resuscitate" decisions? Views of oncology and palliative care doctors and nurses. Indian J Palliat Care. 2012;18:52-58.

8. Matsui M. Perspectives of elderly people on advance directives in Japan. J Nurs Scholarsh. 2007;39:172-176.

9. Clinical Practice Guidelines for Quality Palliative Care [webpage on the Internet]. Pittsburg, PA: National Consensus Project for Quality palliative Care. c2013. Available from: https://www.hpna.org/multimedia/NCP_Clinical_Practice_Guidelines_3rd_Edition.pdf. Accessed December 29, 2015.

10. Howard RJ. Missed opportunities: the institute of medicine report: organ donation: opportunities for action. Am J Transplant. 2007;7:14-16.

\section{Publish your work in this journal}

Advances in Medical Education and Practice is an international, peerreviewed, open access journal that aims to present and publish research on Medical Education covering medical, dental, nursing and allied health care professional education. The journal covers undergraduate education, postgraduate training and continuing medical education including emerging trends and innovative models linking education, research, and health care services. The manuscript management system is completely online and includes a very quick and fair peer-review system. Visit http://www.dovepress.com/testimonials.php to read real quotes from published authors.

Submit your manuscript here: http://www.dovepress.com/advances-in-medical-education-and-practice-journal 